\title{
Low Grade Glioma: A Qualitative Study of the Wait and See Approach
}

\author{
Caroline Hayhurst, Daniel Mendelsohn, Mark Bernstein
}

\begin{abstract}
Background: There is no consensus on the best management of adults with presumed low grade glioma (LGG). Studies have suggested uncertainty and anxiety associated with a wait and see approach contribute to reduced quality of life. This study aims to explore the impact of a diagnosis of LGG, to address concerns regarding the uncertainty of the diagnosis and the role of wait and see from the patient's perspective. Methods: Qualitative research methodology was used. A semi-structured interview was conducted with 24 patients with imaging evidence of LGG but no prior intervention. All patients had been followed for at least one year prior to interview. Verbatim transcripts were subjected to thematic analysis. Results: The median age of participants was 47 (range $21-82$ ) and the median duration of follow-up 37 months (range 12 - 156 months). Fifty percent presented with seizures. Five overarching themes emerged from the data; 1) patients experience initial devastation followed by acceptance and low anxiety; 2) absence of symptoms mitigates anxiety concerning the possibility of progression; 3) patients would prefer to defer surgery until there is progression or a change in their quality of life; 4) anxiety is reduced by trust in the physician; 5) quality of life is not affected by the diagnosis, as fear of morbidity from intervention is greater than the fear of uncertainty. Conclusions: The wait and see approach does not contribute to anxiety or reduction in quality of life in patients with LGG.
\end{abstract}

RÉSUMÉ: Étude qualitative de l'approche d'observation prudente du gliome de bas grade. Contexte : Il n'existe pas de consensus concernant le meilleur traitement des adultes porteurs présumés de gliomes de faible malignité (GFM). Selon certaines études, l'incertitude et l'anxiété associées à une approche d'observation prudente contribue à diminuer la qualité de vie de ces patients. Le but de cette étude était d'explorer l'impact d'un diagnostic de GFM, d'aborder les préoccupations concernant l'incertitude du diagnostic et le rôle de l'approche d'observation prudente du point de vue du patient. Méthode : Nous avons utilisé une méthode de recherche qualitative. Nous avons procédé à une entrevue semi-structurée chez 24 patients dont l'imagerie avait montré la présence d'un GFM et qui n'avaient pas subi d'intervention antérieure. Tous les patients étaient suivis depuis au moins un an au moment de l'entrevue. Les transcriptions verbatim ont été soumises à une analyse thématique. Résultats : L'âge médian des participants était de 47 ans (écart de 21 à 82 ans) et la durée médiane du suivi était de 37 mois (écart de 12 à 156 mois). Cinquante pour cent avaient consulté pour des crises convulsives. Cinq thèmes principaux sont ressortis des données : 1) les patients ont d'abord été accablés puis ils ont accepté la situation et leur niveau d'anxiété a baissé ; 2) l'absence de symptômes atténue l'anxiété concernant la possibilité de progression ; 3) les patients préféreraient retarder la chirurgie jusqu'à ce qu'il y ait progression ou un changement de leur qualité de vie ; 4) l'anxiété est diminuée par la confiance au médecin ; 5) la qualité de vie n'est pas affectée par le diagnostic étant donné que la crainte d'une morbidité reliée à l'intervention est supérieure à la crainte de l'incertitude. Conclusions : L'observation prudente ne contribue pas à l'anxiété ou à la diminution de la qualité de vie des patients porteurs d'un GFM.

Can J Neurol Sci. 2011; 38: 256-261

When a patient presents with imaging evidence of a low grade glioma (LGG) a range of management options are available, including a wait and see policy, biopsy, resection, adjuvant therapy, or combinations of all of these approaches. There is currently no class 1 evidence to favour any particular approach. A randomised trial of early radiotherapy failed to show any difference in overall survival ${ }^{1}$. There is evidence from retrospective case series that gross total resection may carry an advantage in progression free survival ${ }^{2-5}$. Deferring intervention remains a valid option in these patients to avoid treatment related morbidity, and the resultant reduced quality of life associated with treatment.

Health related quality of life has become an increasingly important measure in glioma studies and is particularly relevant in low grade glioma, as most patients are young and will eventually progress, yet the risk of treatment related morbidity is not well supported by clear evidence of a survival benefit.

Quality of life in patients with glioma is often impaired by decreased general performance status and reduced cognitive functioning ${ }^{6}$. In addition, in LGG uncertainty regarding the diagnosis may negatively influence cognitive performance and

From the Division of Neurosurgery, Toronto Western Hospital, University of Toronto, Toronto, Ontario, Canada.

Received August 3, 2010. Final Revisions Submitted October 12, 2010. Correspondence to: Caroline Hayhurst, Division of Neurosurgery, Toronto Western Hospital, West Wing, 4th Floor, 399 Bathurst Street, Toronto, Ontario, M5T 2S8, Canada. 
quality of life ${ }^{7}$, suggesting that intervention with at least a tissue diagnosis may be of benefit to patients' quality of life.

Patients with LGG will often have imaging and follow-up visits spanning many years; how patients function between these visits and to what level their diagnosis affects their life has not been studied. This study aims to explore the impact of a diagnosis of low grade glioma from the patients' perspective using qualitative research methodology to generate an understanding of the physical and emotional burden of a long term disease without cure and to address concerns regarding the uncertainty of the diagnosis and whether there is a need for upfront intervention.

\section{Patients And Methods}

\section{Study design}

This was a prospective qualitative study using a single semistructured interview with patients followed by the senior author (MB) for presumed low grade glioma diagnosed by MR imaging.

\section{Participants}

All patients aged $>18$ with radiological evidence of a low grade glioma, who had not had prior biopsy, resection or adjuvant treatment were invited for interview. All patients had been followed for at least one year prior to interview. Thirty-five patients were identified from the senior authors' patient database as suitable for inclusion. Participants were invited for interview by telephone and provided with written information about the study. Those who agreed to participate were invited for face-to- face interviews but telephone interviews were offered where distance precluded attendance. All interviews were conducted in a private room without the presence of relatives.

\section{Data collection and analysis}

Data collection and analysis in this qualitative study was based on grounded theory where ongoing data analysis leads to further questions to refine evolving theories ${ }^{8}$. As such interviews are conducted until no further themes emerge and saturation is reached, often between 25 - 30 interviews ${ }^{9}$. An initial interview guide was developed and subsequent questions added as new themes emerged during the study (see Appendix).

Demographic data for each participant was collected including age, mode of presentation, occupation and duration of follow-up.

Verbatim transcripts of all interviews were prepared and then interview data were examined through modified thematic analysis, which includes open and axial coding ${ }^{10}$. Open coding involves breaking down information into common groupings based on shared ideas, while axial coding involves organizing information according to overarching themes. The transcriptions were analyzed by the investigators who contributed to development of the coding framework.

\section{Research ethics}

Informed consent was obtained from all participants. The study was approved by the Research Ethics Board of the University Health Network.

Table: Demographic details of the 24 study participants

\begin{tabular}{|c|c|c|c|c|c|c|c|c|}
\hline $\begin{array}{l}\text { Study } \\
\text { Number }\end{array}$ & Age & Tumor Location & Occupation & Religion & $\begin{array}{l}\text { Marital } \\
\text { Status }\end{array}$ & $\begin{array}{l}\text { Maximum } \\
\text { Education Level }\end{array}$ & Presentation & $\begin{array}{l}\text { Total Follow-up } \\
\text { (months) }\end{array}$ \\
\hline 1 & 68 & Right frontal & Retired & United & Married & University & Seizures & 156 \\
\hline 2 & 51 & Left frontal & Insurance & Catholic & Married & College & Seizures & 108 \\
\hline 3 & 38 & Left frontal & Housewife & Greek orthodox & Married & College & Incidental & 36 \\
\hline 4 & 29 & Right frontal & Physician & Koptic orthodox & Married & MD & Incidental & 32 \\
\hline 5 & 59 & Left temporal & Immigration & Islam & Married & University & Headaches & 29 \\
\hline 6 & 47 & Right frontal & Factory worker & Orthodox & Married & High School & Incidental & 96 \\
\hline 7 & 51 & Left temporal & Housewife & Catholic & Married & High School & Seizures & 108 \\
\hline 8 & 66 & Right insular & Unemployed & Anglican & Married & College & Seizures & 29 \\
\hline 9 & 54 & Left temporal & Unemployed & Catholic & Married & University & Seizures & 24 \\
\hline 10 & 82 & Right temporal & Retired & United & Widower & High School & Headaches & 60 \\
\hline 11 & 27 & Right frontal & Sales & None & Single & High School & Incidental & 12 \\
\hline 12 & 55 & Right temporal & Store manager & Jewish & Divorced & University & Headaches & 72 \\
\hline 13 & 56 & Left parietal & Unemployed & Catholic & Married & High School & Seizures & 144 \\
\hline 14 & 60 & Tectum & Care worker & Catholic & Single & High School & Incidental & 12 \\
\hline 15 & 68 & Left frontal & Manager & United & Married & College & Headaches & 12 \\
\hline 16 & 39 & Right frontal & Manager & Catholic & Married & University & Seizures & 17 \\
\hline 17 & 29 & Right temporal & Physician & Catholic & Married & $\mathrm{MD}$ & Incidental & 120 \\
\hline 18 & 42 & Left frontal & Construction & Hindu & Married & High School & Seizures & 23 \\
\hline 19 & 26 & Left frontal & Engineer & None & Married & University & Seizures & 24 \\
\hline 20 & 31 & Right frontal & Mortgage advisor & Catholic & Married & University & Headaches & 12 \\
\hline 21 & 21 & Cerebellar & Student & Jewish & Single & University & Headaches & 38 \\
\hline 22 & 47 & Left frontal & Pharmacist & Catholic & Married & University & Seizures & 120 \\
\hline 23 & 30 & Corpus callosum & Manager & Jewish & Married & University & Seizures & 120 \\
\hline 24 & 22 & Left frontal & Driver & Christian & Married & High School & Seizures & 60 \\
\hline
\end{tabular}




\section{RESULTS}

Thirty-five patients were invited to participate and 30 volunteered for interview. A total of 24 patients were interviewed before saturation was reached and form the study cohort. The Table demonstrates the demographic data for each participant. The median age of participants was 47 (range 21 - 82) and the median duration of follow-up 37 months (range 12 - 156 months). Twelve patients $(50 \%)$ presented with seizures, six presented with headaches and six were incidental findings.

\section{Thematic Analysis}

Analysis of the interview transcripts yielded five overarching themes:

\section{Patients experience initial devastation followed by acceptance} and low anxiety

All patients expressed shock and devastation at the initial diagnosis which dissipated quickly with subsequent imaging demonstrating no change in the lesion. Patients felt that the initial diagnosis represented imminent death and where relieved to be told that "wait and see" was an option. Most participants felt their anxiety and uncertainty about the future reduced after the second MRI or approximately one year. All patients reported that at approximately the one year stage they could resume their normal lives and make future plans again.

“After the first year as I saw it wasn't changed I relaxed and now I don't think about it anymore".

Serial imaging induces anxiety in most patients in the few days prior to the appointment but does not have an impact in the intervening time.

“As soon as I've found out it hasn't changed, it's over, that's it, bang!"

Although patients reported that they became overtly anxious or withdrawn in the few days leading up to the next scan, none believed this had a negative impact on their life.

"Anxious, I cry more readily, I get angry more easily. I worry that it's changed... I only worry for a few days before each appointment".

\section{Absence of symptoms mitigates anxiety concerning the} possibility of progression

Neurological symptoms are viewed as a direct marker of tumor behaviour and patients' perception of risk of progression is directly linked to the presence or absence of symptoms. Most patients at the time of interview were either asymptomatic or had seizures which were controlled on medication and were therefore happy to pursue a wait and see approach and not consider intervention.

"I worry that it's changed, but I focus more on the symptoms". Most patients correlated symptoms to the severity of disease and were vigilant for potential symptoms at which point they felt that intervention would be warranted.

"I'm guided by the symptoms I might expect and I don't have any".
Of those patients who presented with seizures (50\%), where seizures were controlled on medication, most felt that medical treatment of their condition was sufficient. One patient has ongoing focal seizures, despite anticonvulsant therapy and has more anxiety regarding malignant progression than the rest of the participants.

\section{Patients would prefer to defer surgery until there is progression or a change in their quality of life.}

Overwhelmingly, given the option, all patients wished to pursue a wait and see approach, rather than consider upfront intervention. Most regarded the option of serial imaging as reassurance of the low grade nature of their lesion.

"I would take the wait and see option. Unless symptoms happened to take over and reduce my quality of life, but right now it's manageable".

"Well, if it hasn't changed I'd leave it alone. As long as I'm symptom free there is no reason for me to have any surgery".

Although patients understand and accept that a radiological diagnosis has limitations, a biopsy and tissue diagnosis is of little value to patients independently. The issue of uncertainty has very little impact on patients. Eighty-five percent of participants stated that obtaining a histological diagnosis would not change their quality of life in any way. me".

"Knowing a name for it would make very little difference to

"You've got to look at risk reward... why do a biopsy when...if it is something it'll show up on the next scan, right?"

When considering the potential risk of morbidity with surgical intervention, participants wished to defer surgery until there was a clear indication, such as radiological progression or a decline in their own functional level. At this stage the risk of any neurological deficit became acceptable.

"I would feel most comfortable with surgery if something had changed".

\section{Anxiety is reduced by trust in the physician}

All patients were happy with the reassurance provided by their physician based on serial imaging, regarding the nature of the lesion. All those interviewed felt that they received enough information at follow-up visits and did not seek additional information on long-term prognosis.

"I had reassurance that it was likely benign, so I just carried on with life".

Easy access to office visits and the ability to ask questions both at visits and in-between visits, via telephone or email, were significant factors in reducing anxiety in the long-term. While a minority of patients would be comfortable to have telephone follow-up for imaging results, most felt that face-to-face interaction and the ability to go through their scans with the physician was helpful to them.

However, when asked to consider upfront surgical intervention, the majority of patients stated that they would want firm evidence of benefit from early resection in terms of survival or seizure control, before accepting the risks of morbidity. 
"If you gave me statistics then I would consider it [surgery], but right now you can't guarantee it so I might as well stay as I am".

5. Quality of life is not affected by the diagnosis, as fear of morbidity from intervention is greater than the fear of uncertainty

All participants viewed themselves as healthy and most did not think their quality of life had been adversely affected by the diagnosis of LGG. Patients felt the greatest impact on their quality of life would be from neurological deficits associated with intervention.

"What would happen to me- would I stay the way I am now, which is normal?"

"I have a busy life with a baby and work...this [surgery] could change everything".

"There's definitely risks and right now I'm trying to live my life to the fullest".

"If it affects my quality of life then it [surgery] is not worth it....if something does come we'll deal with it then".

Very few patients expressed concerns regarding their own future and the implications of the diagnosis of a brain tumor. Most felt that the diagnosis alone had not had a negative impact on their lives or limited them in any way. In those presenting initially with seizures five (42\%) felt that the diagnosis of epilepsy, with the need for ongoing medication and loss of their driving licence, had the greatest negative impact on their quality of life.

\section{Discussion}

Using qualitative research methods to explore the issues of uncertainty and anxiety, we demonstrate that the wait and see policy without tissue diagnosis does not contribute to anxiety and reduced quality of life in patients with low grade glioma. Symptoms such as ongoing seizures have more negative impact than the uncertainty of tumor progression. The risk of surgery is not viewed as acceptable unless a definitive benefit is demonstrated, either in terms of prolonged survival or alleviation of symptoms.

Few studies in the literature address the cognitive and psychological impact of low grade glioma prior to any intervention. Two studies by Taphoorn et $\mathrm{al}^{11,12}$ focus on the effect of radiotherapy. Patients with LGG do not have significantly impaired performance status, but they do have cognitive impairment ${ }^{11}$. This cognitive impairment exists whether treatment has been undertaken or not, suggesting tumor infiltration and its psychological effects are responsible ${ }^{12}$. Fatigue is also a severe problem in patients with low grade glioma ${ }^{13}$. Patients with low grade glioma had significantly lower results on most neuropsychological variables than controls with hematological malignancy ${ }^{14}$. Mood states and well-being were significantly lower in patients with LGG than in healthy controls ${ }^{15}$.

Where LGG has been managed conservatively it has been suggested that uncertainty regarding the diagnosis may influence cognitive performance and quality of life ${ }^{7}$. Reijneveld et al (2001) assessed cognitive performance and quality of life in patients with suspected LGG and those with proven (operated)
LGG, demonstrating that a wait and see policy had no negative impact on cognitive performance status or quality of life ${ }^{16}$. Using the Brain Cancer Module 20 questionnaire that study demonstrated no difference in the future uncertainty criteria between the two groups. Patients who underwent resection or biopsy scored worse on quality of life and cognitive status measures. The contribution of surgical morbidity to this difference in neuropsychological scores is difficult to assess. Qualitative research methodology is a potentially more sensitive tool to measure issues such as uncertainty, fear and its negative impact on quality of life. Our study demonstrates that in conservatively managed LGG fear of intervention has the greatest impact and that uncertainty is minimal. Overall all participants felt that their quality of life had not been affected by the diagnosis. Therefore our study and that of Reijneveld et al ${ }^{16}$ conclude that a definitive diagnosis by biopsy does not lead to a reduction in anxiety or uncertainty and has no role in improving quality of life.

Qualitative research provides the ideal tool to learn more about the burden of a long-term disease process from the patient perspective. Edvardsson et al have used qualitative methodology to describe both patient and next-of kin perceptions of the onset and diagnosis of LGG, with particular emphasis on coping mechanisms ${ }^{17-19}$. Assessment of quality of life in LGG can be divided into broad categories: onset of illness, current life situation and experiences of encounters with health professionals. Edvardsson et al describe the onset of illness as the most distressing time ${ }^{19}$. This critical period at the initial diagnosis has a significant impact on the next of kin, which again dissipates over time ${ }^{18}$. Positive and negative experiences of encounters with healthcare professionals were strong themes in patient interviews, with repeated visits to multiple physicians contributing to distress ${ }^{19}$. Negative experiences involved lack of information. In our study patients were happy with the level of information they received. Continuity and trust was a significant theme contributing to reduction in anxiety levels in our study. Our study also highlights patient perceptions of the label 'low grade glioma', as highlighted by the patient quote 'I had reassurance that it was likely benign'. All patients are informed of the natural history of LGG and malignant transformation, but appear to perceive the adoption of the wait and see approach as evidence of a chronic nature of the disease.

Edvardsson et al demonstrated that being permitted to participate in and influence decisions regarding management was a significant positive theme ${ }^{19}$. This element of participation is also reflected in our study with patients reporting a wish to defer intervention until they themselves felt ready to accept the risk of additional morbidity. Our study is unique as it specifically addresses anxiety generated by the wait and see approach from the patients perspective, while previous studies have selected patients with a confirmed histological diagnosis who have undergone treatment.

\section{Limitations}

The potential limitations of the current study are that it represents a single institution experience of a group of conservatively managed patients with LGG. The results may not extend to other cultures, health care systems, and patient populations. The study cohort are potentially self selected as 
those radiological LGG lesions considered potentially more aggressive had already undergone intervention and are excluded from the study cohort. It is the senior author's policy to offer surveillance imaging and the wait and see approach in LGG patients unless treatment is indicated for clinical and/or imaging reasons (e.g. mass effect from the tumor) and/or the patient prefers treatment up-front. At the time of first presentation all patients are presented with all the options, including observation and surgery. In addition, the natural history of low grade glioma is explained, including malignant transformation. It is also explained that the senior authors' preference is surveillance imaging. It is clear from this study, that given these facts a large number of patients still wish to pursue a conservative approach, without a negative impact on their current lives. The study cohort demonstrates low levels of overall anxiety and minimal impact on quality of life in a population where it is postulated anxiety would have a major negative impact. For comparison, in the past five years 15 patients underwent surgery at initial diagnosis of low grade glioma, representing approximately $40 \%$ of the LGG cohort.

Another limitation is the potential for bias against up-front intervention by the interviewer but this is hopefully reduced by qualitative research methodology using semi-structured interviews which allows themes to freely emerge with minimal direction from the interviewer.

\section{Conclusion}

The findings from this study give valuable insight into patients' coping mechanisms when faced with a diagnosis of a suspected low grade glioma, beyond that obtained from Quality of Life measures used as adjuncts to clinical trials. Patients experience high levels of anxiety at the time of diagnosis, which rapidly dissipates. Overall, uncertainty or fear of future malignant progression has little impact on patients, who fear morbidity from treatment more than the prospect of future malignant progression, as long as it is felt that the wait and see approach is safe. This information is valuable when counselling patients on the management options in LGG, a disease in which there is no definitive evidence that up-front treatment confers improved survival.

(See Appendix on following page)

\section{REFERENCES}

1. van den Bent MJ, Afra D, de Witte O, et al. Long-term efficacy of early versus delayed radiotherapy for low-grade astrocytoma and oligodendroglioma in adults: the EORTC 22845 randomised trial. Lancet. 2005; 366(9490):985-90.

2. Smith JS, Chang EF, Lamborn KR, et al. Role of extent of resection in the long-term outcome of low-grade hemispheric gliomas. J Clin Oncol. 2008; 26(8):1338-45.

3. McGirt MJ, Chaichana KL, Attenello FJ, et al. Extent of surgical resection is independently associated with survival in patients with hemispheric infiltrating low-grade gliomas. Neurosurgery. 2008; 63(4):700-7; author reply 707-8.

4. Rezvan A, Christine D, Christian H, et al. Long-term outcome and survival of surgically treated supratentorial low-grade glioma in adult patients. Acta Neurochir (Wien). 2009; 151(11):1359-65.

5. Sanai N, Polley MY, Berger MS. Insular glioma resection: assessment of patient morbidity, survival, and tumor progression. J Neurosurg. 2010; 112(1):1-9.

6. Osoba D, Aaronson NK, Muller M, et al. Effect of neurological dysfunction on health-related quality of life in patients with high-grade glioma. J Neurooncol. 1997; 34(3):263-78.

7. Kash KM, Holland JC, Osborne MP, Miller DG. Psychological counseling strategies for women at risk of breast cancer. J Natl Cancer Inst Monogr. 1995; 17:73-9.

8. Kennedy TJ, Lingard LA. Making sense of grounded theory in medical education. Med Educ. 2006; 40(2):101-8.

9. Strauss A, Corbin J. Basics of qualitative research: techniques and procedures for developing grounded theory. Thousand Oaks, CA: Sage Publications; 1998.

10. Pope C, Mays N, Ziebland S. Analysing qualitative data. In: Pope C, May N, editors. Qualitative research in health care. London: BMJ Books; 2000. p. 78.

11. Taphoorn MJ, Heimans JJ, Snoek FJ, et al. Assessment of quality of life in patients treated for low-grade glioma: a preliminary report. J Neurol Neurosurg Psychiatry. 1992; 55(5):372-6.

12. Taphoorn MJ, Schiphorst AK, Snoek FJ, et al. Cognitive functions and quality of life in patients with low-grade gliomas: the impact of radiotherapy. Ann Neurol. 1994; 36(1):48-54.

13. Struik K, Klein M, Heimans JJ, et al. Fatigue in low-grade glioma. J Neurooncol. 2009; 92(1):73-8.

14. Klein M, Heimans JJ, Aaronson NK, et al. Effect of radiotherapy and other treatment-related factors on mid-term to long-term cognitive sequelae in low-grade gliomas: a comparative study. Lancet. 2002; 360(9343):1361-8.

15. Taphoorn MJ, Heimans JJ, Snoek FJ, et al. Quality of life and neuropsychological functions in long-term low-grade glioma survivors. Int J Radiat Oncol Biol Phys. 1994; 29(5):1201-2.

16. Reijneveld JC, Sitskoorn MM, Klein M, et al. Cognitive status and quality of life in patients with suspected versus proven lowgrade gliomas. Neurology. 2001; 56(5):618-23.

17. Edvardsson T, Ahlstrom G. Illness-related problems and coping among persons with low-grade glioma. Psychooncology. 2005; 14(9):728-37.

18. Edvardsson T, Ahlstrom G. Being the next of kin of a person with a low-grade glioma. Psychooncology. 2008; 17(6):584-91.

19. Edvardsson T, Pahlson A, Ahlstrom G. Experiences of onset and diagnosis of low-grade glioma from the patient's perspective. Cancer Nurs. 2006; 29(5):415-22. 


\section{APPENDIX}

\section{INTERVIEW GUIDE}

\section{PREAMBLE:}

We are trying to learn more about the impact of the diagnosis of low grade glioma on your life and your opinion of the information provided to you at each visit. This will help us have a better understanding of the problems you face and improve future communication.

\section{QUESTIONS:}

1. How did you find out you had a brain tumor? Please describe what happened and how you were told.

- What was your reaction/how did this make you feel?

- What were your first thoughts about the future?

- Were you shocked, upset, angry, numb? Tell me more.

2. What information were you given about the management options?

- How did you feel about not having surgery or a biopsy at the moment? Does this worry you?

- Do you worry about surgery or treatment in the future?

- What or who helped you decide what to do?

3. What information were you given on the long-term outlook?

- How did this make you feel?

- Is it what you expected? Tell me more.

4. Has the diagnosis changed your life in any way?

- Does the brain tumor limit what you can do?

- Have you changed anything in your life because of the diagnosis?

- Has it affected your family or friends?

- Tell me more

5. What are your fears and concerns about your brain tumor and how it will affect your life? Tell me more about it.

6. What do you think will happen in the future? Have you thought about it? Do you talk to anyone about this? Tell me more

7. How do you feel before your next scan? Do you think about it often? Does it change what you do or how you act with people close to you? What are you worried about? Tell me more.

8. What information are you given at your follow-up visits? How does this make you feel? Is it what you expected? Would you want anything else from these visits? Tell me more.

9. Does the fact that the medical profession are uncertain of the best treatment add to your worries? Are you angry or upset with the medical profession for not giving you a clear answer?

10. Is there anything else that is on your mind or worries you that we haven't covered?

\section{Additional questions developed during the study:}

How do you rate your quality of life?

Do you think having a definitive diagnosis would alter your quality of life? - for the worse or better?

Do you view yourself as healthy or unhealthy?

Do you find seeing the imaging helpful?

Some would suggest surgery should be done early although it is at present unclear that this improves overall out come- how would you feel about accepting the risk of complications in this situation? 